\title{
Fibres and asbestos bodies in bronchoalveolar lavage fluids of asbestos sprayers
}

\author{
Timo Tuomi, Panu Oksa, Sisko Anttila, Olavi Taikina-aho, Eero Taskinen, Antti Karjalainen, \\ Pentti Tukiainen
}

\begin{abstract}
The alveolar content of fibres and asbestos bodies was assessed by bronchoalveolar lavage (BAL) in 21 asbestos sprayers. Transmission and scanning electron microscopy (TEM and SEM) and two light microscopical (LM) methods, cytocentrifugation, and Millipore filtration were used. The subjects had been exposed mainly to crocidolite asbestos for an average of 2.8 (range 0.2-13) years in 1950-75. The mean (median) total fibre count (of asbestos bodies and uncoated fibres) per $\mathrm{ml}$ of BAL fluid was 5500 (2800) by TEM and 2900 (1000) by SEM. The mean (median) count of asbestos bodies per $\mathrm{ml}$ with $\mathrm{LM}$ was 810 (500) with cytocentrifugation and 750 (480) with Millipore filtration, 840 (320) by TEM, and 1750 (420) by SEM. The mean proportion of coated fibres was $35 \%$ by TEM and $45 \%$ by SEM. The mean length of the coated fibres was 22 (range 4-65) $\mu \mathrm{m}$ by TEM and 34 (range 4.5-170) $\mu \mathrm{m}$ by SEM. The total fibre count exceeded 1000 fibres per $\mathrm{ml}$ in $\mathbf{7 0} \%$ of the cases by TEM. Asbestos body counts exceeded 1 per $\mathrm{ml}$ in $95 \%$ of the cases by $L M$. The fibre counts by SEM were in good accordance with counts by TEM except in a few cases in which the TEM result was considerably higher. In these cases the proportion of coated fibres was also low. All four counting methods appeared to give consistent results in heavily exposed cases when fibre load in the lungs was high. The counting of asbestos bodies may, however, underestimate the total alveolar fibre load in some cases.
\end{abstract}

Institute of Occupational Health, Helsinki, Finland

T Tuomi, P Oksa, S Anttila, A Karjalainen

Institute of Electron Optics, University of Oulu

O Taikina-aho

Department of Chest Medicine, Helsinki University Central Hospital

P Tukiainen

Transplantation Laboratory, University of Helsinki

E Taskinen
The diagnosis of asbestos related diseases is essentially based on information from the patients' work history of exposure to asbestos. In some occupations in which indirect contacts to materials containing asbestos are common, the exposure cannot be explicitly documented. This problem arises in the construction industry, where asbestos was commonly used up to the 1970s, and the exposure of all workers is probable but apparently with variation in intensity.

Bronchoalveolar lavage is a non-invasive method used to study the amount of inorganic particles in the lower respiratory tract. ${ }^{1}$ Studies on several individual subjects and occupational groups and unexposed reference groups have shown the analysis of asbestos bodies and fibres from bronchoalveolar lavage fluid (BAL) to be a reliable method for indicating past exposure. ${ }^{2-4}$ Coated and uncoated fibres can be found a long time after cessation of exposure. ${ }^{5}$ The number of asbestos bodies in BAL fluid has also been shown to correlate well with the parenchymal concentration. ${ }^{46}$ Although the counting of asbestos bodies has commonly been performed with a light microscope, several studies based on electron microscopical counting techniques have been published..$^{7-12}$ The advantages of the electron microscope are a higher resolution which allows thin uncoated fibres to be counted, and its ability in combination with $x$ ray microanalysis to identify the fibre types. The sensitivity at lower concentrations of asbestos bodies has, nevertheless, been shown to be better with light microscopy. ${ }^{8}$

In this study we wanted to describe the exposure to asbestos as the number of fibres in BAL fluid among asbestos sprayers, and to compare methods using the electron microscope and the light microscope.

\section{Materials and methods}

SUBJECTS

The 21 subjects of the study were chosen from a total of 61 former asbestos sprayers whose health state had been examined in 1987 at the Institute of Occupational Health, Helsinki. Of the total group $28 \%$ had asbestosis, $5 \%$ had suspected asbestosis, $30 \%$ had pleural changes caused by asbestos, and $13 \%$ had non-diagnostic radiological abnormalities 
or abnormalities of pulmonary function. The criteria for selection to the BAL group were abnormalities on $x$ ray film, or in pulmonary function, or both, that definitely diagnosed or suggested lung or pleural fibrosis. The 21 voluntary male subjects had been employed in enterprises that performed asbestos spraying in the construction industry and in shipbuilding between 1956 and 1975 . The spraying time of the subjects was relatively short (mean 2.8 (range $0 \cdot 2-13$ ) years). Half of the subjects had performed asbestos spraying for less than 1.4 years. They had typically started spraying work in the 1960 s, but eight had started in 1970 or later. The mean time since the first year of asbestos spraying was 22 (range 15-30) years. As well as asbestos spraying they had typically worked for several years in other occupations with probable exposure to asbestos. Eleven subjects had worked in the construction industry and five in shipbuilding. Eleven had been exposed to asbestos for the first time in spraying work and the remaining 10 were exposed on average six years before the spraying work period. Sixteen subjects had worked in occupations with probable exposure to asbestos after spraying work. Two of the subjects had had no other exposure than that during spraying.

The mean age of the patients in the study year (1989) was 47 (range 39-58). Their clinical state was examined, they were questioned about their work history, and chest radiographs were taken. Pulmonary fibrosis (International Labour Office (ILO) class $\geqslant 1 / 0$ ) was found in $19 \%$ and pleural plaques in $25 \%$ of the subjects; $43 \%$ of the subjects were smokers, $47 \%$ were ex-smokers, and $10 \%$ never smokers. A detailed report of the clinical findings will be given elsewhere.

Bronchoalveolar lavage was performed on the subjects with a fibreoptic bronchofiberoscope (Olympus) under local anaesthesia. ${ }^{13}$ The middle lobe was chosen for lavage. The tip of the bronchoscope was wedged into the subsegmental bronchus. Ten $20 \mathrm{ml}$ aliquots of physiological buffered saline were infused into the same site and the mean recovery rate was $60 \%$ of the infused fluid.

\section{SAMPLE PREPARATION FOR ELECTRON MICROSCOPY}

A sample volume of $20 \mathrm{ml}$ BAL fluid was poured into a $50 \mathrm{ml}$ polyethylene centrifuge tube and the transport tube was washed twice with $3 \mathrm{ml}$ of $50 \%$ ethanol. The mixture was then centrifuged for 20 minutes at $1800 \mathrm{~g}$. The supernatant was partly removed and 20 $\mathrm{ml}$ of filtered $(0.22 \mu \mathrm{m}$ millipore filter $)$ sodium hypochlorite was added to the sediment and incubated for 1.5 hours at room temperature. The mixture was centrifuged again and the supernatant was removed. After standing in an ultrasonic bath for 30 seconds, the sample was filtered on to a nuclepore filter (pore size $0 \cdot 1 \mu \mathrm{m}$ ). The centrifuge tube was washed twice with distilled and filtered water and the washings were added to the filter.
For counting by scanning electron microscopy (SEM), a sector of the sample filter was coated with gold in a sputtering device (JEOL JFC 1100). The sample for transmission electron microscopy (TEM) was prepared using the modified Jaffe washer technique. $^{14}$

COUNTING OF FIBRES AND ASBESTOS BODIES WITH TEM The fibre counting and mineral identification were done with a JEOL 100CX-ASID4D electron microscope $(100 \mathrm{kV})$ and LINK AN10/25 $x$ ray microanalyser. At least 20 grid squares of 150 mesh copper grid were counted at a magnification of 10000 . All fibres were analysed and their lengths and widths were measured. Single fibrils of chrysotile could be detected; an analytical sensitivity of 25 to 66 fibres per $\mathrm{ml}$ was achieved by this method.

COUNTING OF FIBRES AND ASBESTOS BODIES WITH SEM Fibres were counted with a JEOL 100 CX-ASID4D electron microscope in SEM-mode at an acceleration voltage of $40 \mathrm{kV}$. The length of the asbestos bodies and the length and width of each uncoated fibre were measured. Identification of fibre by microanalysis was not done with SEM. A magnification of 5000 was used in the counting. Typically $200-400$ viewing fields were evaluated to find at least four fibres and up to 30 fibres per sample, depending on the fibre density. With this procedure, an analytical sensitivity of 26 to 150 fibres per $\mathrm{ml}$ could be achieved.

\section{COUNTING OF ASBESTOS BODIES WITH LIGHT MICROSCOPY}

(LM; CYTOCENTRIFUGATION METHOD)

Five to $10 \mathrm{ml}$ of BAL fluid were digested in the same amount of $5 \% \mathrm{KOH}$ at $60^{\circ} \mathrm{C}$ for 30 minutes. The sample was then centrifuged at $680 \mathrm{~g}$ for 10 minutes and washed twice with distilled water. The pellet was suspended in $5 \mathrm{ml}$ of distilled water and for the cytocentrifuge preparations samples of $100 \mu \mathrm{l}$ and $200 \mu \mathrm{l}$, three of each, were taken while keeping the test tube in the ultrasonic bath. The samples were centrifuged with a Shandon Cytospin 2 cytocentrifuge at $170 \mathrm{~g}$ for 10 minutes. If no asbestos bodies were found in the preparations, a new sample was centrifuged, suspended in $1 \mathrm{ml}$ of distilled water, and the whole sample was analysed. Asbestos bodies were counted with a phase contrast microscope at a 250 fold magnification.

\section{ASBESTOS BODY COUNTING WITH LM (MILLIPORE FILTRATION METHOD)}

For the Millipore filtration method $1 \mathrm{ml}$ of BAL fluid was fixed in $1 \mathrm{ml}$ of $96 \%$ ethanol. A millipore filter (pore size $8 \mu \mathrm{m}$ ) preparation with Papanicolaou staining was made using commercial filtation equipment with a slight negative pressure. Asbestos bodies were counted by screening systematically each consecutive visual field of the filter with $20 \times$ objective 
magnification (final magnification 350).

If the average number of asbestos bodies exceeded five per visual field a different method of quantification was applied. The size of the rectangular filter was measured in units of visual field and consequently the surface area of the filter was determined. Simultaneously the average number of asbestos bodies from all fields of a vertical and a horizontal traverse over the filter was counted. Finally, the total count of the asbestos bodies per $\mathrm{ml}$ of BAL fluid was obtained.

\section{STATISTICAL ANALYSES}

The Spearman Correlation test was applied to analyse the correlation between the fibre counts and data on work history.

\section{Results}

\section{CONCENTRATION OF FIBRES AND ASBESTOS BODIES IN} BAL FLUID

A wide range of asbestos fibre and asbestos body concentrations was found (table 1). The total fibre concentration generally ranged from a few hundred fibres per $\mathrm{ml}$ to a few thousand fibres per $\mathrm{ml}$ of BAL fluid. Three subjects with several years of spraying had over 10000 fibres per $\mathrm{ml}$ of BAL fluid by TEM. On average, $35 \%$ of the fibres were coated and defined as asbestos bodies as measured with TEM. The relative percentage of coated fibres varied from less than $4 \%$ to $83 \%$ of the total fibre count; $45 \%$ of all fibres were coated as measured with SEM. All fibres could be identified by TEM and $x$ ray microanalysis. Crocidolite constitute $95 \%$ of the total fibres. Only a few anthophyllite, amosite, chrysotile and tremolite fibres were found. The figure illustrates the ratio of coated fibres (LM; Millipore filter method) to total fibres (TEM). The mean ratio was 0.3 and large variation existed with no apparent correlation with total fibre concentration. No statistically significant correlations between the time since the first spraying and the fibre concentrations were found with any of the four methods. A weak correlation existed, however, between the spraying time and the total fibre concentration as well as asbestos body concentration as measured with the four methods. The correlation was statistically significant at the $5 \%$ level with all fibre counts except asbestos body counts with SEM and LM (Millipore filter method).

Table 2 summarises the averge fibre counts with the four methods. The total fibre and asbestos body concentrations, as measured with TEM and SEM, were generally in good agreement (Spearman correlation coefficients $0.73-0.87, \mathrm{p}<0.001)$. The total fibre concentrations were on average lower and the asbestos body concentrations were higher on SEM compared with TEM. The average values for the asbestos bodies were the same with TEM and LM but higher with SEM, and LM was the most sensitive method for detecting asbestos bodies. Several asbestos bodies per $\mathrm{ml}$ were found by LM in three patients in whom no asbestos bodies were found by electron microscopy. Two subjects had less than 1 asbestos body per $\mathrm{ml}$ with the LM and cytocentrifugation techniques, and one with the Millipore filtration technique.

Three groups were formed according to the duration of asbestos spraying-namely, less than one

Table 1 Exposure data and concentrations of coated and uncoated fibres in BAL fluids of the 21 subjects

\begin{tabular}{|c|c|c|c|c|c|c|c|c|}
\hline \multirow{2}{*}{ Age } & \multirow{2}{*}{$\begin{array}{l}\text { Time since } \\
\text { the first } \\
\text { spraying } \\
(y)\end{array}$} & \multirow{2}{*}{$\begin{array}{l}\text { Total time } \\
\text { in asbestos } \\
\text { spraying } \\
(y)\end{array}$} & \multicolumn{6}{|c|}{ Total fibres and asbestos bodies per $m l B A L$} \\
\hline & & & \multicolumn{2}{|l|}{$T E M$} & \multicolumn{2}{|l|}{$S E M$} & \multicolumn{2}{|c|}{$L M(A B)$} \\
\hline $\begin{array}{l}43 \\
48 \\
54 \\
50 \\
48 \\
50 \\
43 \\
44 \\
48 \\
45 \\
42 \\
41 \\
47 \\
58 \\
39 \\
47 \\
47 \\
49 \\
52 \\
45 \\
50\end{array}$ & $\begin{array}{l}25 \\
20 \\
25 \\
21 \\
21 \\
19 \\
21 \\
25 \\
19 \\
21 \\
20 \\
16 \\
15 \\
22 \\
16 \\
25 \\
24 \\
30 \\
28 \\
23 \\
28\end{array}$ & $\begin{array}{r}0.2 \\
0.4 \\
0.5 \\
0.5 \\
0.7 \\
0.8 \\
0.8 \\
0.8 \\
1.0 \\
1.0 \\
1.4 \\
1.5 \\
1.5 \\
2.0 \\
3.0 \\
3.3 \\
3.5 \\
5.9 \\
7.0 \\
10.0 \\
13.0\end{array}$ & $\begin{array}{r}77 \\
3800 \\
800 \\
1600 \\
1100 \\
66 \\
4400 \\
360 \\
25 \\
3000 \\
6900 \\
3400 \\
3200 \\
300 \\
2800 \\
37000 \\
1000 \\
22000 \\
2700 \\
18000 \\
4600\end{array}$ & $\begin{array}{r}26 \\
320 \\
<66 \\
210 \\
1100 \\
<66 \\
2400 \\
220 \\
25 \\
300 \\
270 \\
1200 \\
1900 \\
250 \\
1300 \\
1600 \\
800 \\
<800 \\
1100 \\
4000 \\
680\end{array}$ & $\begin{array}{r}78 \\
680 \\
400 \\
1000 \\
2200 \\
26 \\
4000 \\
300 \\
78 \\
420 \\
3400 \\
3800 \\
3500 \\
360 \\
1100 \\
13000 \\
900 \\
730 \\
4400 \\
19000 \\
1800\end{array}$ & $\begin{array}{r}26 \\
260 \\
100 \\
210 \\
830 \\
<26 \\
3500 \\
160 \\
26 \\
<100 \\
2300 \\
2800 \\
2900 \\
160 \\
760 \\
13000 \\
750 \\
<150 \\
2100 \\
6900 \\
420\end{array}$ & $\begin{array}{r}<1 \\
170 \\
6 \\
950 \\
700 \\
<1 \\
1300 \\
120 \\
56 \\
20 \\
1600 \\
1700 \\
1200 \\
79 \\
500 \\
5200 \\
12 \\
14 \\
1600 \\
1300 \\
500\end{array}$ & $\begin{array}{r}1 \\
140 \\
<1 \\
900 \\
520 \\
9 \\
480 \\
68 \\
12 \\
44 \\
540 \\
890 \\
1800 \\
50 \\
900 \\
2100 \\
930 \\
9 \\
3800 \\
2100 \\
470\end{array}$ \\
\hline
\end{tabular}

$\mathrm{AB}=$ Asbestos body; CCF = cytocentrifugation; $\mathrm{LM}=$ light microscopy; MiPo = Millipore filtration; SEM = scanning electron microscopy; TEM = transmission electron microscopy. 
year, one to five years, and over five years. A statistically non-significant tendency for increasing total fibre concentration (TEM) was seen in these groups with mean concentrations of $1500(n=8)$, $6400(n=9)$, and $12000(n=4)$ fibres per ml respectively.

One of the subjects died of lung cancer in 1991 and

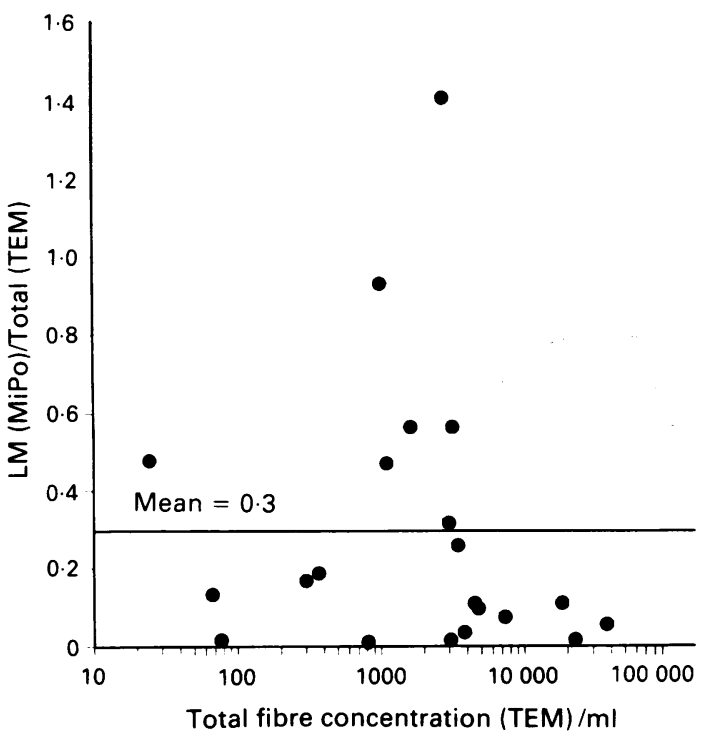

The proportion of asbestos bodies as measured with light microscopy (Millipore filter method) to total fibre concentration (uncoated fibres and asbestos bodies) as measured with TEM in BAL fluids of 21 asbestos sprayers. fibre analysis was done on lung tissue. He had been working in asbestos spraying for one year and the total fibre concentration in BAL fluid was 3000 fibres per $\mathrm{ml}$ (asbestos body concentration 44 per $\mathrm{ml}$ by $\mathrm{LM}$ (Millipore filter method)). The lung fibre concentration was 190 million fibres per $\mathrm{g}$ dry tissue as measured with SEM.

FIBRE SIZE

Table 3 presents the fibre and asbestos body dimensions. The coated fibres were on average four times longer than the uncoated ones. No coated fibres shorter than $4 \mu \mathrm{m}$ were found. About half of the fibres over $5 \mu \mathrm{m}$ in length were coated. No significant difference was found between the width of the coated and uncoated fibres. The median values of the fibre length were similar with both electron microscopical methods. The mean and median fibre widths were, nevertheless, higher than SEM.

\section{Discussion}

The subjects had been exposed to high concentrations of crocidolite fibres and they can be considered as a relatively uniformly exposed group. No data exist for fibre concentrations during asbestos spraying in Finland but the fibre concentrations during asbestos spraying in ships were recorded as $170-320$ fibres per $\mathrm{cm}^{3} .{ }^{15}$ According to the sprayers, the use of respirators was uncommon, especially in the 1960s. The fibre concentrations in the BAL fluid were in the range of the highest concentrations measured among any occupational group..$^{3101116}$

Table 2 The average values of the spraying time and the concentrations of fibres in the BAL fluids of the 21 asbestos sprayers

\begin{tabular}{|c|c|c|c|c|c|c|c|}
\hline \multirow[b]{2}{*}{ Spraying time } & \multirow[b]{2}{*}{$(y)$} & \multicolumn{2}{|c|}{ Total fibre concentrations $(\mathrm{f} / \mathrm{ml})$} & \multicolumn{4}{|c|}{ Asbestos body concentrations ( $A B / m l)$} \\
\hline & & $T E M$ & $S E M$ & $T E M$ & $S E M$ & $L M / C C F$ & $L M / M i P o$ \\
\hline $\begin{array}{l}\text { Mean } \\
\text { Median } \\
\text { Minimum value } \\
\text { Maximum value }\end{array}$ & $\begin{array}{c}2 \cdot 8 \\
1 \cdot 4 \\
0 \cdot 2 \\
13\end{array}$ & $\begin{array}{r}5500 \\
2800 \\
<25 \\
37000\end{array}$ & $\begin{array}{r}2900 \\
1000 \\
<26 \\
19000\end{array}$ & $\begin{array}{r}840 \\
320 \\
<66 \\
4000\end{array}$ & $\begin{array}{r}1750 \\
420 \\
<26 \\
13000\end{array}$ & $\begin{array}{l}810 \\
500 \\
<0 \cdot 2 \\
5200\end{array}$ & $\begin{array}{r}750 \\
480 \\
<1 \\
3800\end{array}$ \\
\hline
\end{tabular}

For definitions see footnote to table 1 .

Table 3 Sizes of coated and uncoated fibres in the BAL fluids as measured with electron microscope

\begin{tabular}{|c|c|c|c|c|}
\hline & \multicolumn{2}{|c|}{$T E M$ fibres } & \multicolumn{2}{|c|}{ SEM fibres } \\
\hline & uncoated & coated & uncoated & coated \\
\hline $\begin{array}{l}\text { Length }(\mu \mathrm{m}) \text { : } \\
\text { mean } \\
\text { median } \\
\text { range }\end{array}$ & $\begin{array}{l}6 \cdot 7 \\
5 \cdot 0 \\
1 \cdot 0-39\end{array}$ & $\begin{array}{l}22 \\
20 \\
4 \cdot 0-65\end{array}$ & $\begin{array}{l}8 \cdot 8 \\
5 \cdot 3 \\
1 \cdot 5-100\end{array}$ & $\begin{array}{l}34 \\
27 \\
4 \cdot 5-170\end{array}$ \\
\hline $\begin{array}{l}\text { Width }(\mu \mathrm{m}): \\
\text { mean } \\
\text { median } \\
\text { range }\end{array}$ & $\begin{array}{l}0 \cdot 15 \\
0 \cdot 10 \\
0 \cdot 01-1 \cdot 0\end{array}$ & $\begin{array}{l}0.14 \\
0 \cdot 10 \\
0 \cdot 01-0.4\end{array}$ & $\begin{array}{l}0 \cdot 38 \\
0 \cdot 30 \\
0 \cdot 1-2 \cdot 0\end{array}$ & $\begin{array}{l}\text { nd } \\
\text { nd } \\
\text { nd }\end{array}$ \\
\hline
\end{tabular}

nd $=$ Not done; for other definitions see footnote to table 1 . 
In three cases the asbestos body count was less than 1 per $\mathrm{ml}$ with both LM methods. In these samples the fibre counts were consistently rather low with electron microscopy. Crocidolite and anthophyllite asbestos fibres were, however, found in these samples.

Crocidolite dominated the alveolar fibre burden of all the subjects, despite the long working time of some subjects in the construction industry with exposure to other types of asbestos as well. This indicates strongly that their total lung fibre burden was essentially accumulated during their working period in asbestos spraying. For the five subjects who had been working in shipyards and in other occupations other exposure to crocidolite in significant amounts could have taken place. The variation in fibre concentrations between subjects with comparable spraying time and the lack of a linear relation between the time spent in asbestos spraying work and alveolar fibre load was obvious and may be due to several reasons like differences in exposure and variations in the lavage technique. Repeated lavages were not done in this study but a good reproducibility in fibre counting from BAL fluid with more than 1 asbestos body per $\mathrm{ml}$ has been found in patients with lavage time intervals of 15 days to five years. ${ }^{5}$

The proportion of coated fibres varied greatly and was generally high, more than one third of all fibres, as compared with the findings of lung parenchyma. The average proportion of asbestos bodies has been reported to be $1 \%$ of the total fibres in the lung parenchyma. ${ }^{17}$ In analysis of lung tissue from urban dwellers, less than $0.5 \%$ of the amosite or crocidolite fibres were coated. ${ }^{18}$ The different proportions of coated fibres may reflect the fact that fibres in the alveolar spaces are longer than in the insterstitium and thus have a higher probability of becoming coated.

The average lengths of the coated and uncoated fibres differed but their widths were essentially the same. Compared with the mean and median sizes of the crocidolite fibres in the lung tissue of mesothelioma patients exposed mainly in shipbuilding, 2.5 times longer uncoated fibres were found in the BAL fluids of the asbestos sprayers. ${ }^{19}$ Half of the uncoated fibres appeared to be longer than $5 \mu \mathrm{m}$. This is a somewhat higher proportion than the median length of approximately $2 \mu \mathrm{m}$ found in the Italian study of persons exposed to asbestos. ${ }^{8}$

In two recent studies the asbestos body concentrations in BAL fluid and lung parenchyma were compared. ${ }^{46}$ The conclusion of both studies was that the parenchymal concentration can be successfully predicted by analysis of asbestos bodies in BAL fluid, although there was large variation in the ratio of alveolar to parenchymal asbestos bodies. The measured BAL concentration of 1 asbestos body per $\mathrm{ml}$ corresponds to a lung concentration of $1000-3000$ asbestos bodies per $\mathrm{g}$ of dry tissue. Thus the mean concentrations of asbestos bodies in the BAL fluid of the asbestos sprayers of this study predict a lung concentration of the order of 1-10 million per $g$ of dry tissue. In addition to the lung fibre concentration of 190 million fibres per $\mathrm{g}$ measured in one of the subjects of this study by SEM, a total fibre concentration of 3000 million fibres per $\mathrm{g}$ of dry tissue (SEM) has been measured in the lungs of a Finnish asbestos sprayer with mesothelioma. ${ }^{19}$

The light microscopical counting of asbestos bodies appears to be a reliable method of conclusively indicating exposure in this group. The electron microscope is needed in cases where identification of fibres is of interest to attribute them to specific exposure. The major limitation of both electron microscopical methods was the high detection limit encountered in a reasonable counting time. The sample preparation method used here did not allow the utilisation of sample volumes larger than $20 \mathrm{ml}$ without excessive amounts of residue particles on the sample filters.

We thank M-L Vakkari, MSc and Ms S-L Sarpola for their help in preparing the samples and in LM counting, and $\mathrm{H}$ Keskinen, $\mathrm{MD}$ and $\mathrm{H}$ Nordman, $\mathrm{MD}$ for performing some of the lavages. The study was supported by the Finnish Work Environment Fund and the Finnish Academy of Sciences.

Requests for reprints to: Timo Tuomi, Institute of Occupational Health, Topeliuksenkatu 41 a A, SF-00250 Helsinki, Finland.

1 Dumortier P, De Vuyst P, Yernault JC. Non-fibrous inorganic particles in human bronchoalveolar lavage fluids. Scanning Microsc 1989;3:1207-18

2 Barbers RG, Abraham JL. Asbestosis occurring after brief inhalation exposure: usefulness of bronchoalveolar lavage in diagnosis. $\mathrm{Br} J$ Ind Med 1989;46:106-10.

3 Di Menza L, Hirsch A, Sebastien P, Gaudichet A, Bignon J. Assessment of past asbestos exposure in patients: occupational questionnaire versus monitoring in broncho-alveolar lavage. In: Wagner JC, ed. Biological effects of mineral fibres. Lyon: International Agency for Research on Cancer, 1980;609-14. (IARC Sci publ No 30.)

4 Sebastien P, Armstrong G, Monchaux G, Bignon J. Asbestos bodies in bronchoalveolar lavage fluid and in lung parenchyma. Am Rev Respir Dis 1988;137:75-8.

5 De Vuyst P, Dumortier P, Moulin E, Yourassowsky N, Yernault JC. Diagnostic value of asbestos bodies in bronchoalveolar lavage fluid. Am Rev Respir Dis 1987;136:1219-24.

6 De Vuyst P, Dumortier P, Moulin E, Yourassowsky N, Roomans P, de Francquen P, Yernault JC. Asbestos bodies in bronchoalveolar lavage reflect lung asbestos body concentration. Eur Respir J 1988;1:362-7.

7 Bignon J, Sebastien P, Gaudichet A, Bientz M. Analysis of mineral particles recovered by broncho-alveolar lavage for the diagnosis of dust related lung diseases. Am Rev Respir Dis 1978;117:218.

8 Chiappino G, Friedrichs KH, Rivolta G, Forni A. Alveolar fiber load in asbestos workers and in subjects with no occupational asbestos exposure: an electron microscopy study. Am J Ind Med 1988;14:37-46.

9 De Vuyst P, Mairesse M, Gaudichet A, Dumortier P, Jedwab J. Mineralogical analysis of bronchoalveolar lavage fluid as an aid to diagnosis of "imported" pleural asbestosis. Thorax 1983;38:628-9. 
10 Dumortier P, De Vuyst P, Strauss P, Yernault JC. Asbestos bodies in bronchoalveolar lavage fluids of brake lining and asbestos cement workers. $\mathrm{Br} J$ Ind Med 1990;47:91-8.

11 Gellert AR, Kitajewska JY, Uthayakumar S, Kirkham JB, Rudd RM. Asbestos fibres in bronchoalveolar lavage fluid from asbestos workers: examination by electron microscopy. $\mathrm{Br} J$ Ind Med 1986;43:170-6.

12 Johnson NF, Haslam PL, Dewar A, Newman-Taylor AJ, Turner-Warwick $M$. Identification of inorganic dust particles in bronchoalveolar lavage macrophages by energy dispersive $x$-ray microanalysis. Arch Environ Heath 1986;41:133-44.

13 Leskinen R, Taskinen E, Volin L, Tukiainen P, Ruutu T, Häyry $P$. Use of bronchoalveolar lavage cytology and determination of protein contents in pulmonary complications of bone marrow transplant recipients. Bone Marrow Transplant 1990;5:241-5.

14 Chatfield EJ. Short mineral fibres in airborne dust. In: Chatfield EJ, Elmes PC, Muhle H, Pott F, Pooley FD, eds. Short and thin mineral fibres. Identification, exposure and health effects.
Solna, Sweden: National Board of Occupational Safety and Health Research Department, 1983;10-93.

15 Harries PG. Asbestos dust concentrations in ship repairing: a practical approach to improving asbestos hygiene in naval dockyards. Ann Occup Hyg 1971;14:241-54.

16 De Vuyst $P$, Jedwab J, Dumortier $P$, Vandermoten $G$, Vande Weyer R, Yernault JC. Asbestos bodies in bronchoalveolar lavage. Am Rev Respir Dis 1982;126:972-6.

17 Davis JMG, Gylseth B, Morgan A. Assessment of mineral fibres from human lung tissue. Thorax 1986;41:167-75.

18 Churg A, Warnock L. Asbestos fibers in the general population. Am Rev Respir Dis 1980;122:669-78.

19 Tuomi T. Fibrous minerals in the lungs of mesothelioma patients: comparison between data on SEM, TEM, and personal interview information. Am J Ind Med 1991;19: $155-62$.

Accepted 4 November 1991 